\title{
RESEÑA DEL LIBRO: MEDIA AND METAMEDIA MANAGEMENT
}

\author{
PUENTES-RIVERA, IVÁN \\ Universidad de Vigo \\ ivanpuentes@uvigo.es
}

https://doi.org/10.17979/redma.2016.01.017.4866

El libro Media and Metamedia Management es una obra publicada a comienzos de 2017 por la editorial Springer, tanto en versión electrónica como impresa, escrita íntegramente en inglés y cuyos responsables, en su rol de editores, son los profesores gallegos Francisco Campos Freire, Xosé Rúas Araújo, Valentín Alejandro Martínez Fernández y Xosé López García, pertenecientes a las Universidades de Santiago de Compostela (USC), A Coruña (UDC) y Vigo (UVigo).

La publicación forma parte, además, de los trabajos llevados a cabo por la Red Internacional de Investigación de Gestión de la Comunicación, XESCOM, un proyecto de investigación (Ref. R2014/026) financiado en régimen de concurrencia competitiva por la Consellería de Cultura, Educación y Ordenación Universitaria de la Xunta de Galicia, liderado por el grupo de Novos Medios de la USC y coordinado conjuntamente con éste por los grupos iMarka (UDC) y NECOM (UVigo). En dicho proyecto participan también diversos investigadores de las Universidades Fernando Pessoa, Azores y do Minho en Portugal, de la Universidad Autónoma de Tamaulipas en México y de las Universidades Técnica Particular de Loja y Pontificia Católica Sede Ibarra en Ecuador.

Junto con este carácter internacional, iberoamericano concretamente, de su producción, destaca desde el punto de vista del contenido por la inclusión de 66 trabajos originales, firmados por 118 autores de 31 universidades españolas, 
portuguesas, inglesas y ecuatorianas. Entre ellos, se encuentran los artículos de ocho expertos en comunicación de reconocido prestigio (Miquel de Moragas, Javier Guallar, Andreu Casero Ripollés, Raphael Cohen Almagor, Estrella Gualda, Israel Márquez, Jaime Cabeza Pereiro y Emma Rodríguez Rodríguez), en los que plasman sus reflexiones sobre el presente y futuro del periodismo, la publicidad, el sector audiovisual y la comunicación corporativa y política, prestando especial atención al papel de Internet y las redes sociales en el desarrollo de estos campos.

En este sentido, el lector encontrará en todos los casos trabajos que versan sobre temas de máxima actualidad, desde el uso con fines terroristas que de la Red hacen determinados grupos islamistas, la curación de contenidos en medios digitales o el potencial de Internet para acciones de movilización y activismo político, hasta el derecho a la intimidad digital en el entorno de trabajo y los servicios de información pública en la era digital, pasando por el valor que aportan los metamedios en el nuevo ecosistema digital, la calidad y ética del periodismo en ellos desarrollado, la inmediatez como valor temporal o las posibilidades que en el terreno de la eficacia abre la aplicación al estudio de la comunicación de técnicas y herramientas originalmente propias de las neurociencias, dando lugar así a la llamada neurocomunicación.

El libro se distribuye en ocho capítulos temáticos, además de una introducción a cargo de los editores, dedicados a los nuevos medios en la era digital, el periodismo y ciberperiodismo, el sector audiovisual y la economía de medios, la comunicación corporativa e institucional, el marketing, la publicidad y el turismo, Internet y redes sociales, nuevos medios y metamedios y, por último, educación ciencia e identidad cultural. Es decir, se reflexiona con varios trabajos y diversos objetos de estudio en cada caso sobre cada uno de los principales ámbitos profesionales de la comunicación social. 
Todo ello a fin de adquirir conocimientos que permitan actuar de un modo más efectivo en el nuevo ecosistema digital. La irrupción de Internet y las tecnologías de la comunicación y la información, particularmente de las redes sociales, en el ámbito de la comunicación no sólo ha propiciado la transformación de los medios clásicos, sino que ha provocado una completa transformación de la denominada sociedad de la información, en la que se relacionan e interactúan constantemente millones de ciudadanos y organizaciones de todo tipo.

Surgen en este contexto los llamados metamedios, medios que trascienden ampliamente el concepto tradicional de los mismos, que ofrecen a los públicos múltiples posibilidades y plataformas de comunicación y en el que los roles de emisor y receptor se funden, pasando uno y otro a ejercer ambos papeles. Se crea, efectivamente, un auténtico ecosistema en el que multitud de especies interactúan y conviven, en el que los cambios en uno de los elementos del mismo influyen en todos los demás, manteniendo entre sí un equilibrio similar al de cualquier ecosistema natural.

Esta transformación no sólo afecta a la industria de la comunicación y la información, o a la de la producción cultural, afecta a la totalidad de sectores e industrias y no sólo a la producción o relaciones comunicativas, en sentido amplio, entre actores dentro de cada uno de esos sectores, sino que afecta a todos los ámbitos de los mismos; además de los mencionados, también se producen cambios radicales en la comercialización e incluso en la propiedad de las diferentes formas de valor.

Por ello, el libro Media and Metamedia Management no es una obra centrada exclusivamente en el ámbito de las industrias comunicativas, informativas o culturales, sino que proporciona una visión amplia, que aborda los cambios que la nueva gestión de la comunicación derivada del entorno digital obliga a 
implementar en diferentes sectores económicos, así como en la esfera de la comunicación pública o institucional.

Así, entre las 515 páginas del libro se encuentran trabajos de investigación centrados en el derecho a la intimidad en prensa, en nuevas formas, incluso géneros, de periodismo, en la influencia social de los medios tradicionales y digitales, en las transformaciones experimentadas por los grupos de comunicación nacionales y europeos, en los cambios en las audiencias, la ficción o las diferentes formas de financiación a las que recurren en la actualidad las industrias culturales; en la comunicación organizacional 2.0, en las nuevas tendencias en comunicación política y electoral, pero también en los cambios que todo ello está provocando en el terreno del marketing, en la promoción de destinos turísticos, en la docencia e investigación universitarias, en el eficacia de la publicidad o en el diseño web.

Se trata, en definitiva, de un libro que posee una doble alma, académica y profesional. Al igual que entre sus autores se encuentran destacados investigadores universitarios, pero también reconocidos profesionales de diferentes ámbitos de la comunicación, la obra pretende servir de guía tanto a académicos interesados en abordar proyectos de investigación relacionados con redes sociales y gestión de la comunicación en el mencionado ecosistema digital, como a profesionales de múltiples sectores que necesitan claves y recursos para operar con mayor eficacia comunicativa en ese entorno. 